\title{
ANAESTHESIA FOR THE SURGICAL CORRECTION OF SCOLIOSIS BY THE HARRINGTON METHOD IN CHILDREN*
}

\author{
J. E. S. ReLTON, M.B., B.S., $\bar{D} . A .$, F.F.A.R.C.S., $\nmid$ AND \\ A. W. CoNN, M.D., B.SC., F.R.C.P.(C), F.A.C.A. $\$$
}

Scoliosis is a relatively common/disease and is said to occur in 1 per cent of the population in the United States. ${ }^{1}$ Ninety per cent of cases require no treatment because the deformity is minimal, ${ }^{2}$ but severe cases frequently require surgical correction. A new method of operative correction and stabilization devised by Harrington $^{3}$ combines spinal fusion with internal metallic fixation. This paper deals with the anaesthetic management of cases treated by this method. Special reference will be made to the preoperative assessment and the problem of blood loss at operation.

Scoliosis has been defined as "any' lateral curve, tilt, or angular deviation of one or more vertebral segments of the spine from the normal vertical position." The disease may be classified into two types: functional and structural.

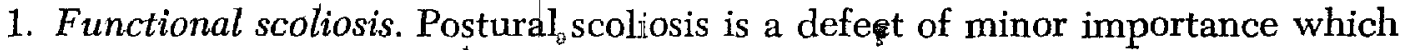
can be corrected voluntarily and maintained in a satisfactory position. Compensatory scoliosis may occur as a result of a primary skeletal alteration (e.g. secondary to disparity in leg length).

2. Structural scoliosis. This disease differs in aetiology, pathology, prognosis, and treatment from the preceding type. It can be classified aetiologically ${ }^{5}$

Congenital: With or without X-ray evidence of vertebral defects.

Acquired:

(i) Idiopathic ( $80 \%$ of cases of structural scoliosis and of this group $85 \%$ are female).

(ii) Neuromuscular: following poliomyelitis or in association with neurofibromatosis, syringomyelia, Freidreich's ataxia, paraplegia.

(iii) Thoracic disease: empyema," thoracoplasty.

(iv) Vertebral disease: tuberculosis, tumour, fracture dislocation, osteomalacia.

In the present series there were 44 cases with structural scoliosis. The average age was 12.2 years and 75 per cent were female. Only 13 cases were idiopathic $(29.2 \%)$; the majority of cases had the more severe forms of deformity (e.g., congenital, paraplegic or following meningomyelocele) and required a far more extensive operative procedure than the conventional spinal fusion (Fig. 1).

\footnotetext{
'Presented at the Annual Meeting of The Canadian Anaesthetists' Society, Montebello. Quebec, May 13-16, 1963.

fFellow in Clinical Anaesthesia, Hospital for Sick Children, Toronto.

†Chief of Anaesthesia, Hospital for Sick Children, Toronto and Assistant Professor of Anaesthesia, University of Toronto.
} 


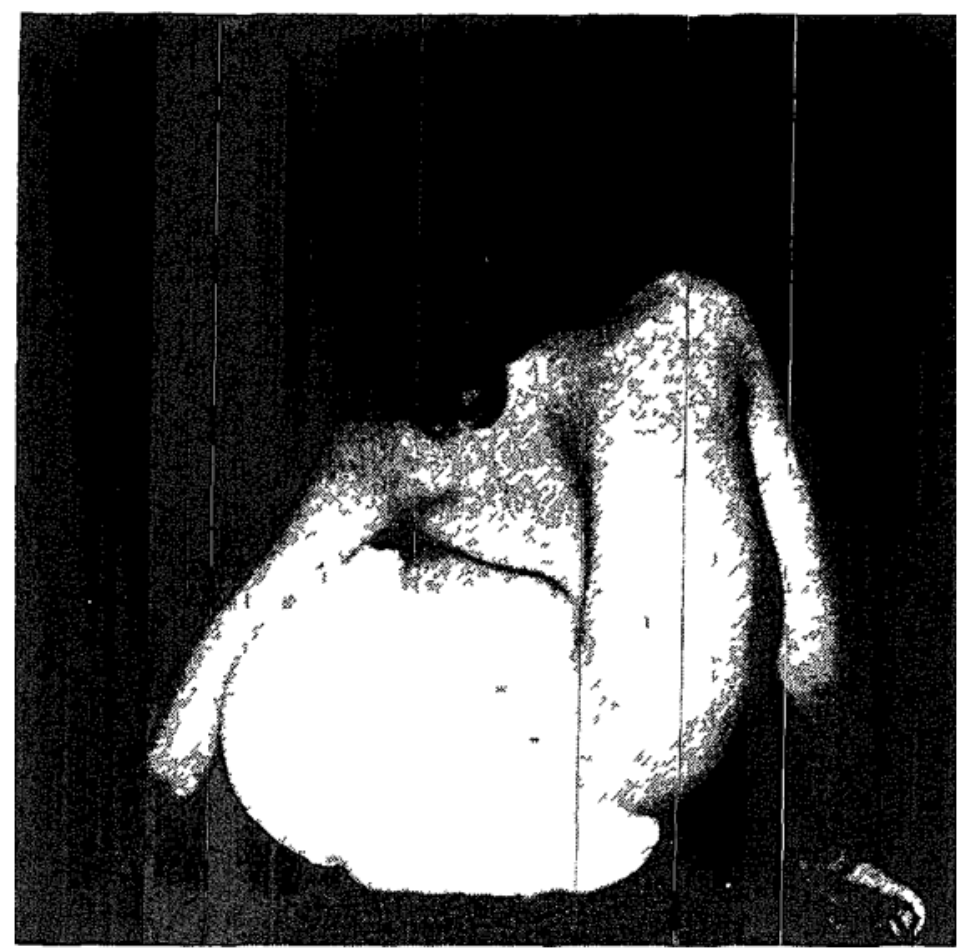

Ergure 1. Severe kyphoscoliosis complicating amyotonia congenita.

\section{SYMPTOMS}

Postural deformity with unsightliness is the main complaint in childhood and adolescence. The onset of scoliosis may occur at any stage of growth but aggravation of the deformity usually occurs during the period of rapid growth from 10 to 14 years. The earler the onset of the disease, the greater the resultant deformity. Although cardiorespiratory symptoms resulting from scoliosis are unusual in childhood, early treatment is recommended to avoid later cardıorespiratory disability.

\section{Cardionespiratory Effects of Severe Scoliosis}

In childhood, cosmetic appearance of spinal deformity causes greater concern than possible effects on cardiorespiratory physıology. The mechanical effects of severe scoliosis on respiratory function and pulmonary haemodynamics have been evaluated recently. ${ }^{5}{ }^{8} 7 \mathrm{It}$ is known that the deformity can lead to cardrorespiratory failure of sudden onset in middle age. Caro and Dubois, using a wide range of pulmonary function tests, investigated 38 patients with scolıosis. They found that lung volumes were below average and compliance reduced, and that these changes can be mimicked in the normal subject by strapping the chest tightly, thereby occluding part of the lung to ventilation. Bergofsky and his co-workers correlated the cardiac, respiratory, and pathological changes with the degree and severity of the curvature. They found that the work and energy cost of breathing is high because of the high elastic resistance of the chest wall. The cardiorespiratory failure which may occur is associated with small lungs and low maximal 
breathing capacity. As a result, progressive alveolar hypoventilation occurs leading to hypoxia, hypercapnoea, and respiratory acidosis. The alveolar hypoventilation is associated with an increase in pulmonary vascular resistance, and the resulting pulmonary hypertension may lead to right heart failure. Additional factors have been reported. Post-mortem findings in one case included tracheal compression, pulmonary collapse, and kinking of the pulmonary artery ${ }^{8}$

Zorab found close correlation between the severity of the spinal curvature and the incidence of breathlessness and recommended early treatment. He stressed the importance of maintaining a good spinal position as the most effective means of preventing respiratory insufficiency. If spinal fusion is contemplated to prevent further deterioration in patients with minimal respiratory reserve, accurate preoperative assessment is required. Prime ${ }^{9}$ showed that restrictive ventilatory insufficiency occurs frequently in scoliosis. He found that obstructive airway disease occurred in only 2 cases out of 35 examined. The low respiratory reserve results from an inability to ventilate adequately because of the skeletal deformity and may be aggravated by muscle weakness, as in scoliosis following poliomyelitis.

It is not clear why pulmonary hypertension occurs nor is it known what degree of scoliosis the lungs will tolerate, or why respiratory failure of sudden onset may develop in middle age. ${ }^{10}$

The Surgical Procedure

In this series, the Harrington method was used for the correction of severe scoliosis. ${ }^{11}$ This procedure combines spinal fusion with internal metallic fixation. A system of rods and hooks is implanted and distraction and compression forces applied to correct the curvature. Stabilization of the vertebral segments in the corrected position is maintained by skeletal fixation and spinal fusion.

This procedure is designed to improve cardiorespiratory function, to improve appearance, and to relieve pain. It is also designed to improve tolerance to sitting and standing in paraplegic cases.

The extensive and formidable operative procedure involves the exposure of 10 to 14 vertebrae. It is time-consuming and severe blood loss may occur.

\section{ANAESTHETIC MANÁgEMENT}

Preoperative assessment. The patients were questioned regarding their susceptibility to chest infections and to the quantity of sputum produced; whether respiratory assistance was ever required; and their ability and stamina in walking, , running, and climbing stairs. Using a Wright anemometer and face mask, ventilation was assessed by measuring the resting tidal volume, resting minute volume, vital capacity, and maximal breathing capacity. An arterial blood sample was taken and the $p \mathrm{O}_{2}, \mathrm{O}_{2}$ saturation, $\mathrm{pH}, p \mathrm{CO}_{2}$, and $\mathrm{CO}_{2}$ content measured. The tests are repeated approximately six months postoperatively when the plaster ${ }_{5}$ casts are removed. Serial measurements are taken subsequently to determine any improvement in respiratory reserve. An analysis of the results will be the subject of a future publication. 
In view of the respiratory disability which may be present, careful attention should be given to the ventilation during, anaesthesia and in the postoperative period. Two cases (4.5\%) in this series required tracheostomy and respiratory assistance because of impending ventilatory insufficiency in the postoperative period.

Premedication. All patients received atropine ( $0.6 \mathrm{mg}$ ), meperidine ( $1 \mathrm{mg} . / \mathrm{z}_{4} \mathrm{lb}$. -maximum $100 \mathrm{mg}$.), and/or pentobarbitone (1 mg./lb.) intramuscularly one hour preoperatively.

Induction. A sleep dose of sodium thiopentone was used and suxamethonium given in a dose of $1 \mathrm{mg}$./3lb. Oxygen was administered until complete relaxation occurred. The trachea and cords were sprayed with 4 per cent lignocaine and intubation was performed using either a standard Magill cuffed tube or an armoured latex tube.

Maintenance. Nitrous oxide and oxygen have been used for maintenance in all cases, supplemented by halothane, methoxyflurane, or a muscle relaxant. A recent modification in the surgical technique included extensive infiltration of the operative site with 1:250,000 adrenaline solution to the level of the transverse processes. As a result, the use of halogenated hydrocarbons was discontinued and a technique of nitrous oxide/oxygen combined with $d$-tubocurarine was introduced.

Ventilation. A Bird respirator was used routinely to control ventilation. Spontaneous ventilation was not permitted because of the pre-existing respiratory disability and the restriction to ventilation imposed by the prone position during operation. Satisfactory operating conditions were obtained by using a moderate degree of hyperventilation combined with a negative pressure of $3-5 \mathrm{~cm}$. of water in the expiratory phase. Controlled hyperventilation has several advantages. ${ }^{12}$ The potentially harmful effects of respiratory acidosis are avoided and respiratory alkalosis can be a useful adjuvant to light anaesthesia because cerebral function

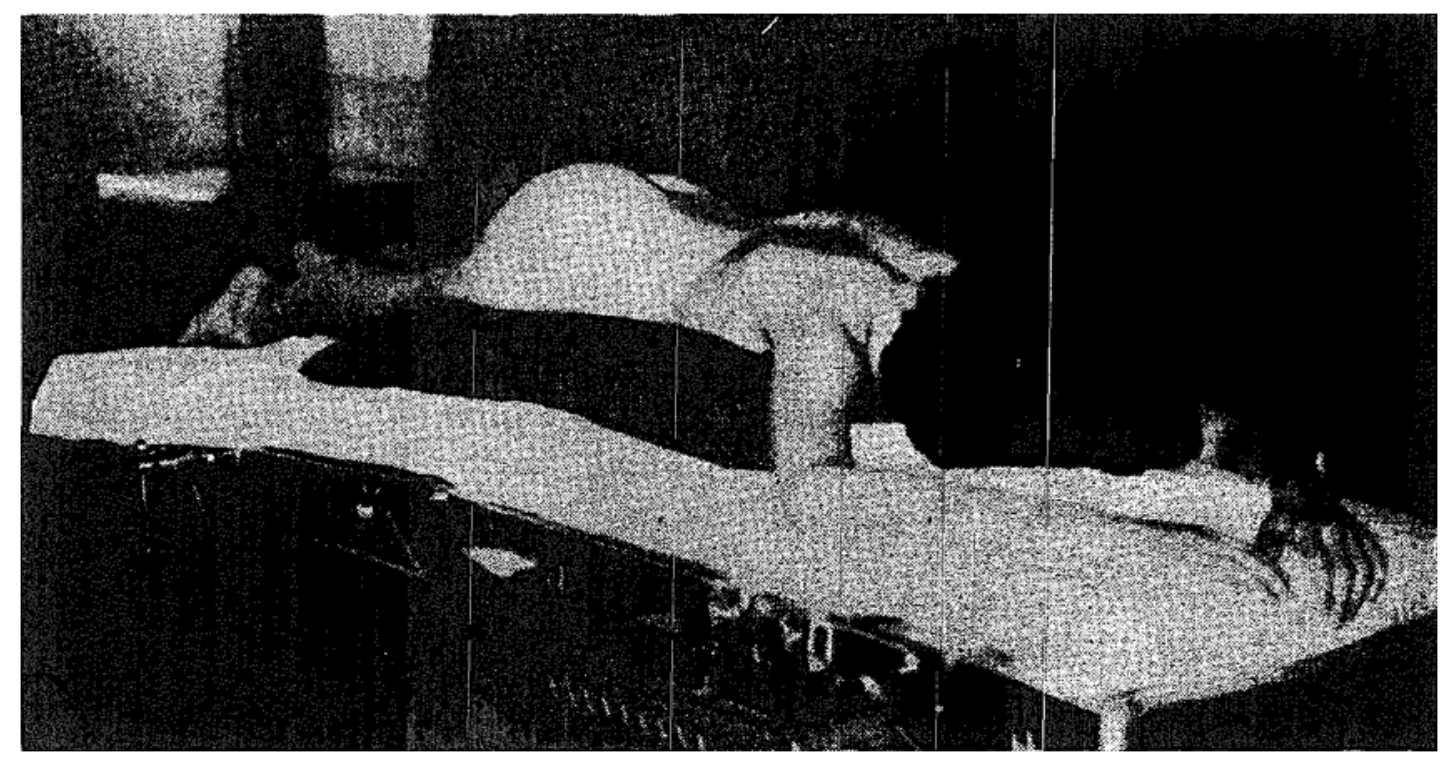

FIGURe 2. Lateral bolsters supporting the patient in the prone position. 
Is depressed, analgesia enhanced, and the total dose of curare reduced. In addition, the heart is protected against the potentially dangerous effects of neostigmine. ${ }^{13}$ Postoperatively, a quicker return is made to a normal blood $\mathrm{pH}$ than from the acidotic state.

Posture. It is necessary for the vertebral column to be slightly flexed and adequately supported during operation and therefore the prone position is essential. Three different methods of support have been used: (1) lateral bolsters extending from the level of the clavicles to the anterior superior iliac spines ${ }^{14}$ (Fig. 2); (2) the MacKay frame" (Fig. 3); and (3) a "tripod method"16 which

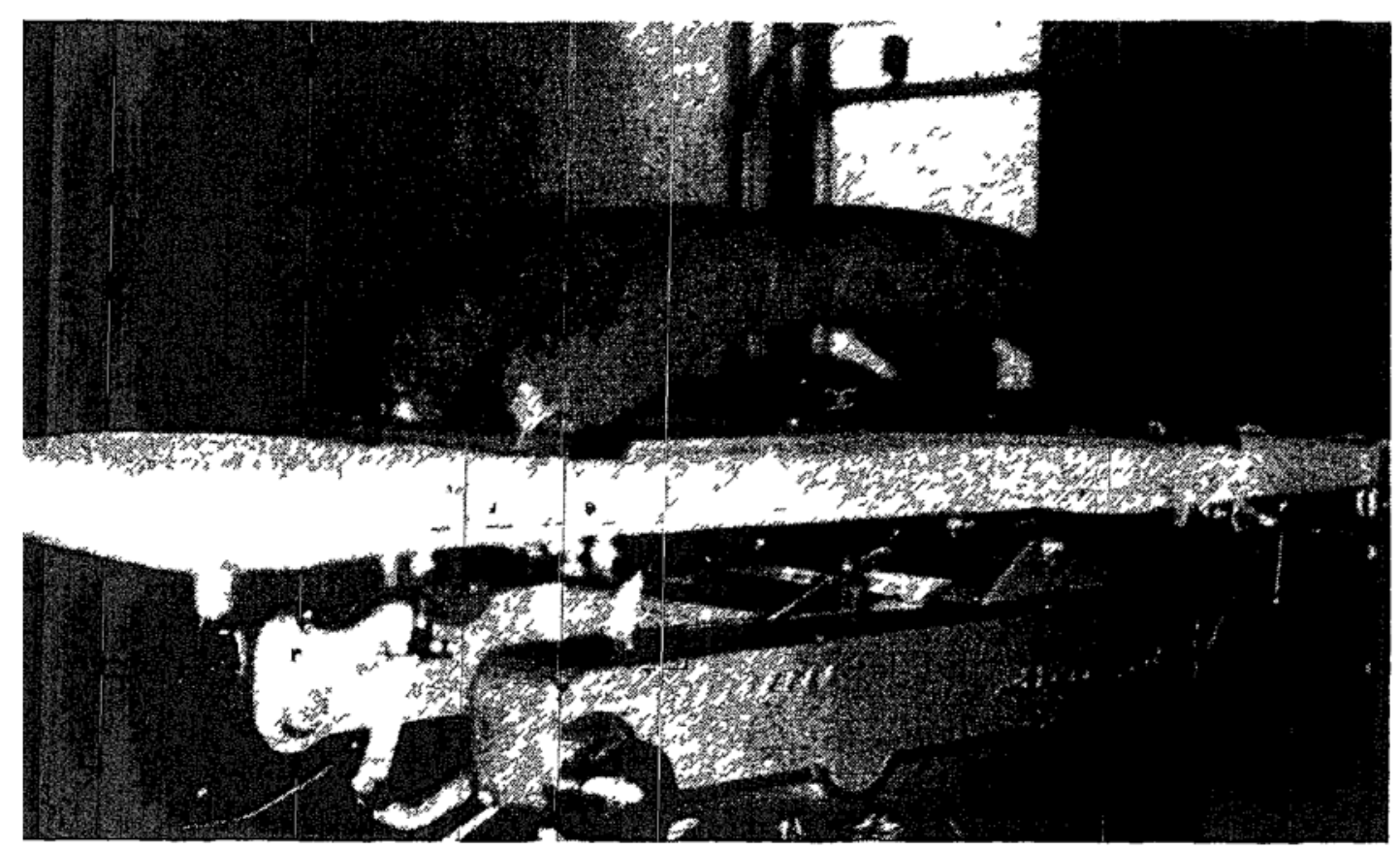

Figure 3. The Mackay frame.

includes a chest support and two lateral supports for the anterior superior iliac spines. This method may cause undesirable hyperextension of the distorted and weakened vertebral column and is therefore not always applicable (Fig. 4). The method of support in the prone position is an important factor in regard to the severe blood loss which may occur during this operation.

Montoring. An oesophageal stethoscope is used routnely. Blood pressure and pulse rate are recorded every five minutes in the course of the anaesthetic. A manometer is attached to the endotracheal tube connector to indicate airway pressure during intermittent positive pressure respiration (I.P.P.R.).

\section{Bloon Loss}

Estımation. Gravimetric methods are used to assess blood loss. Sponges and packs are weighed, losses on the drapes estimated, and the quantity of blood in the suction apparatus measured. Blood loss was a major problem in this series 
(see Table I). It was especially severe in those cases of congenital scoliosis, e.g., following meningomyelocele, which required extensive dissection before fusion and stabilization could be effected. Bonica and Lyter ${ }^{18}$ reported a measured blood loss ranging from 402 to $912 \mathrm{ml}$. in operation on the vertebral column, but the extent of the operations was not specified. With a conventional type of spinal fusion, Thomas ${ }^{19}$ reported a blood loss of 1 to 2 litres.

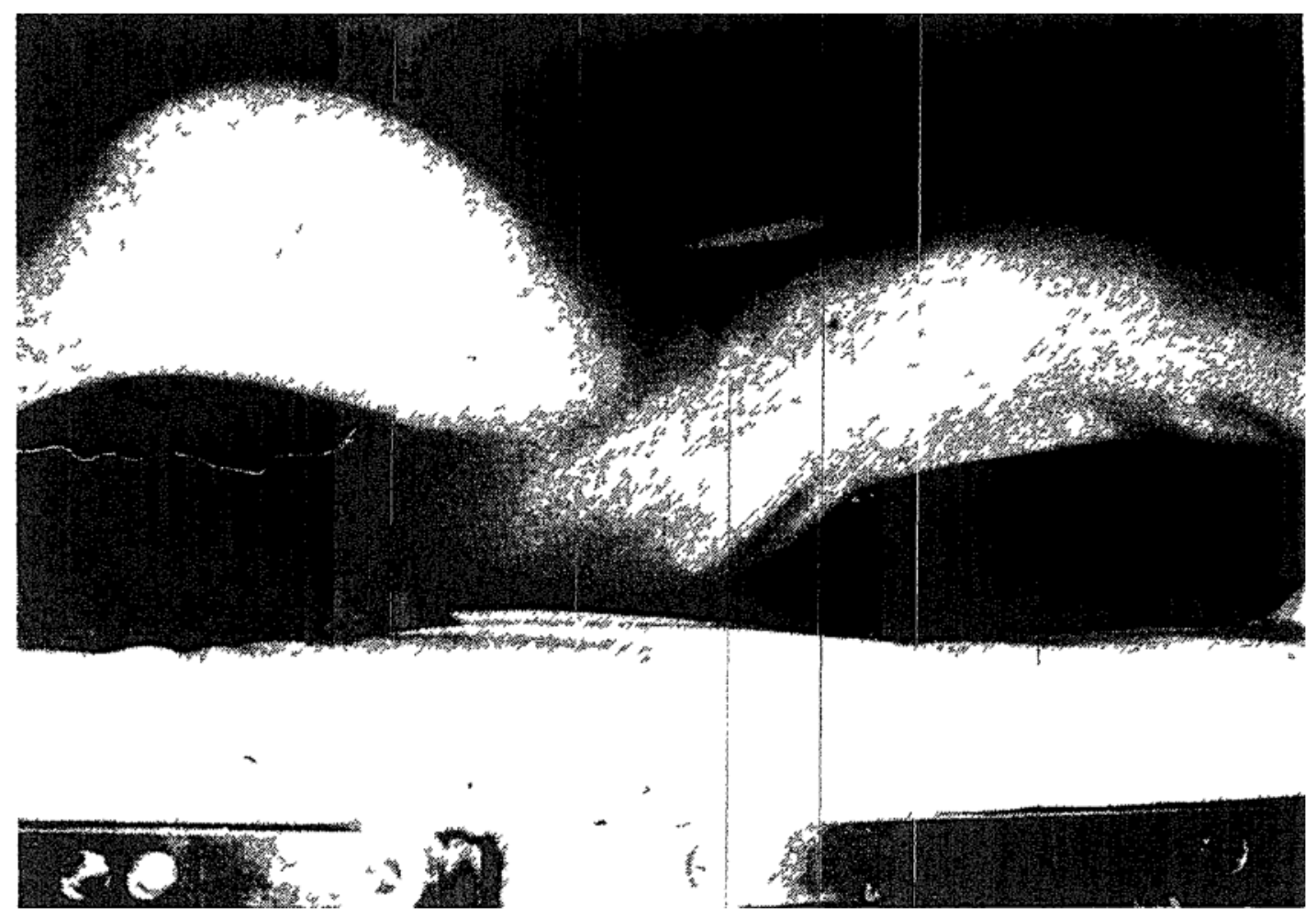

Frgure 4 Hyperextension of the vertebral column due to the "tripod" method of patient support

Blood replacement. A wide-bore intravenous needle (e.g. 15 gauge) is inserted following induction and connected to a blood pump apparatus. A second needle and stilette is inserted in case of need. Blood transfusion should begin cearly in the procedure so that replacement never lags behind the rate of loss. Blood balance is checked at half-hourly intervals. Calcium gluconate $(10 \%)$ is given empirically In assessing blood replacement it is important that postoperative oozing into the extensive wound area be considered.

Haemoglobin level. The preoperative haemoglobin concentration should be 11.5 grams per cent or greater. Following adequate blood volume replaeement, the immediate postoperative haemoglobin concentration is usually satisfactory. However, a fall of $3 \mathrm{gm} . \%$ or more may occur during the first postoperative week because of further oozing into the wound spaces, dzlution, and destruction of a certain percentage of transfused red cells. The percentage of non-viable cells dèpends on the age of the stored blood transfused. ${ }^{20}$ 
TABLE I

Blobd Loss Statistics

\begin{tabular}{|c|c|c|c|c|c|c|c|c|}
\hline \multirow[b]{2}{*}{ No. } & \multirow[b]{2}{*}{ Wt. (kg.) } & \multirow{2}{*}{$\begin{array}{l}\text { Estimated } \\
\text { blood vol. } \\
\text { (litres)* }\end{array}$} & \multirow{2}{*}{$\begin{array}{l}\text { Bllood } \\
\text { loss } \\
\text { (litres) }\end{array}$} & \multirow{2}{*}{$\begin{array}{l}\text { Blood } \\
\text { replaced } \\
\text { (litres) }\end{array}$} & \multirow{2}{*}{$\begin{array}{l}\text { Blood loss } \\
\text { as } \% \text { of } \\
\text { blood } \\
\text { volume } \\
\text { (approx.) }\end{array}$} & \multicolumn{2}{|c|}{ Haemoglobin $(\mathrm{gm} . \%)$} & \multirow{2}{*}{$\begin{array}{c}\text { Total } \\
\text { anaesthetic } \\
\text { time (hr.) }\end{array}$} \\
\hline & & & & & & Preop. & $\begin{array}{l}\text { 1st day } \\
\text { postop. }\end{array}$ & \\
\hline 1 & 26.0 & 2.08 & 3.20 & 4.45 & 154 & 14.7 & 14.1 & 4.75 \\
\hline 2 & 28.3 & 2.27 & 3.30 & 3.20 & 145 & 13.1 & 12.1 & 5.25 \\
\hline 3 & 27.8 & 2.22 & 2.40 & 3.20 & 108 & 13.9 & 13.8 & 4.00 \\
\hline 4 & 384 & 3.07 & 3.30 & 3.80 & 10.7 & 15.5 & 15.4 & 5.75 \\
\hline 5 & 48.7 & 3.90 & 4.10 & 5.00 & 105 & 13.2 & 13.4 & 4.00 \\
\hline 6 & 37.5 & 3.00 & 3.00 & 3.00 & 100 & 12.5 & 11.0 & 4.00 \\
\hline 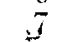 & 26.0 & 2.08 & $2.00^{\circ}$ & 2.33 & 96 & 15.0 & 12.7 & 3.00 \\
\hline 8 & 45.9 & 3.67 & 3.40 & 3.60 & 92 & 12.8 & 9.7 & -4.00 \\
\hline 4 & 16.3 & 1.30 & 1.20 & 1.45 & 92 & 12.2 & 13.1 & 3.00 \\
\hline 10 & 170 & 1.36 & 1.20 & 1.97 & 88 & 11.4 & 13.6 & 3.75 \\
\hline 11 & 37.0 & 2.96 & 2.60 & 3.00 & 87 & 13.6 & & 4.20 \\
\hline 12 & 29.0 & 2.32 & 2.00 & 2.50 & 86 & 14.6 & 13.0 & 3.00 \\
\hline 13 & 34.2 & 2.74 & 2.20 & 2757 & 80 & 13.9 & 14.3 & 4.00 \\
\hline 14 & 34.0 & 2.72 & 2.10 & 3.00 & 77 & 12.7 & 13.0 & 3.75 \\
\hline 15 & 20.9 & 1.67 & 1.25 & 1.70 & 75 & 14.0 & & 3.50 \\
\hline 16 & 34.0 & 2.72 & 2.60 & 2.86 & 75 & 10.7 & 13.3 & 4.75 \\
\hline 17 & $34.0^{\circ}$ & 2.72 & 2.00 & 3.40 & 73 & 13.6 & 14.6 & 4.00 \\
\hline 18 & 29.0 & 2.32 & 1.50 & 2.00 & 64 & 14.0 & 14.4 & 4.00 \\
\hline 19 & 41.0 & 3.28 & 2.10 & 2.65 & 64 & 13.6 & & 5.00 \\
\hline 20 & 33.0 & 2.64 & 1.61 & 2.95 & 61 & 10.4 & 14.0 & 4.00 \\
\hline 21 & 37.0 & 2.96 & 1.78 & 1.88 & 60 & 12.9 & 13.2 & 3.00 \\
\hline $\begin{array}{l}21 \\
22 \\
\end{array}$ & 320 & 2.56 & 1.50 & 1.75 & 58 & 13.4 & 10.9 & 3.00 \\
\hline $2 \pi$ & 42.5 & 3.40 & 1.95 & $2: 00$ & 57 & 14.0 & 12.3 & 4.50 \\
\hline 24 & 29.0 & 2.32 & 1.30 & 1.84 & 56 & 13.6 & 12.6 & 3.00 \\
\hline 25 & 310 & 2,48 & 1.30 & 1.50 & 52 & 15.2 & & 4.25 \\
\hline 26 & 44.5 & 3.56 & 1.88 & 1.95 & 52 & 11.7 & 9.4 & 5.00 \\
\hline 27 & 370 & 2.95 & 1.50 & 1.64 & 50 & 11.4 & 12.0 & 3.50 \\
\hline 28 & 51.0 & 4.08 & 2.00 & 2.15 & 49 & 13.6 & 14.2 & 4.00 \\
\hline 29 & 20.0 & 1.60 & 0.78 & 1.50 & 48 & 12.2 & 15.3 & 3.50 \\
\hline 30 & 40.0 & 3.20 & 1.55 & 1.56 & 48 & $12 . \overline{7}$ & 14.6 & $3: 25$ \\
\hline 31 & 34.3 & 2.74 & 1.30 & 1.50 & 47 & 13.6 & & 3.50 \\
\hline 32 & 45.0 & 3.60 & 1.66 & 2.20 & 46 & 11.7 & 12.8 & 3.33 \\
\hline 33 & 410 & 3.28 & 1.50 & 1.30 & 4.5 & 13.4 & 11.7 & 3.00 \\
\hline 34 & 502 & 402 & 1.80 & 2.50 & 44 & 11.8 & 13.3 & 3.00 \\
\hline 35 & 340 & 2.72 & 1.16 & 1.22 & 42 & 13.1 & & 4.00 \\
\hline 36 & 41.0 & 3.28 & 1.36 & 1.60 & 41 & 14.2 & 13.3 & 3.00 \\
\hline 37 & 450 & 3.60 & 1.43 & 1.87 & 40 & 14.6 & 9.5 & 3.50 \\
\hline 38 & 34.0 & 2.72 & 1.05 & 1.00 & 38 & 13.5 & 10.7 & 2.00 \\
\hline 39 & $51 \leqslant$ & 4.14 & 1.50 & 1.95 & 36 & 13.7 & 14.2 & 3.50 \\
\hline 40 & 427 & 3.42 & 1.19 & 1.44 & 35 & 12.9 & & 3.00 \\
\hline 41 & 46.0 & 3.68 & 1.25 & 2.20 & .34 & 11.5 & 14.2 & 3.25 \\
\hline 42 & 37.2 & 3.00 & 1.03 & 0.97 & 34 & 12.5 & 11.0 & 3.00 \\
\hline 43 & 43.6 & 345 & 1.10 & 1.72 & 31 & 12.5 & $\begin{array}{l}11.0 \\
13.2\end{array}$ & 2.50 \\
\hline 44 & 163 & 1.30 & 0.20 & 0.45 & 15 & 13.4 & 14.6 & 2.00 \\
\hline
\end{tabular}

${ }^{*}$ Blood volume $75-80 \mathrm{ml} . / \mathrm{kg} .{ }^{17}$

\section{FaCtors AfFecting, Blood Loss}

\section{Surgical Factors}

The incision and dissection may be extensive. Profuse bleeding occurs when the erector muscle attachments are stripped from the spinous processes, laminae, and transverse processes. Bleeding is primarily venous in origin from the vertebral venous plexuses. After the spinous processes are removed and the cortex pared 
from the laminae and transverse processes, persistent oozing occurs from a large area of vascular cancellous bone during the period in which the instruments are applied.

\section{Venous Engorgement}

Two factors may cause venous obstruction and engorgement of the vertebral plexuses in the course of this procedure: (1) The prone position causing abdominal compression, and (2) I.P.P.R. causing thoracic obstruction to the venous return.

1. The effect of prone posture. Cruveilhier wrote in 1834 that "the veins of the spine are such that one may consider them in relation to the general circulation as establishing an uninterrupted communication bêtween the veins of all parts of the trunk: so that one may conceive either of the two venae cavae to be obliterated without interruption of the venous circulation." ${ }^{11}$ The vertebral system of veins provides channels through which blood returns to the heart when large venous structures are occluded. There are several plexuses of thin-walled, valveless veins in relation to the vertebral bodies. ${ }^{22}$ They normally contain blood at low pressure and the direction of flow is reversible. Nagore, ${ }^{23}$ in confirming the classical experiments of Batson, ${ }^{24}$ demonstrated that the venous return from the lower parts of the body can be diverted from the inferior vena cava into the vertebral venous system. During anaesthesia, many factors may cause alteration in inferior vena caval pressure and, therefore, cause an obstruction to venous return..$^{25}$

Rollason ${ }^{26}$ and Pearce ${ }^{16}$ have stressed that the prone position is a major factor in the causation of haemorrhage during operations on the vertebral column. Pressure on the anterior abdominal wall is transmitted to the inferior vena cava (I.V.C.). Pearce recorded the high pressures in the I.V.C. which occur during abdominal compression. He demonstrated a marked reduction in haemorrhage during laminectomy in the prone position. when intra-abdominal pressure was minimal. A rise in intra-abdominal pressure may borcaused by muscle tension or by extrinsic factors (e.g., sandbags, bolsters, or the operating table mattress). $\mathrm{He}$ recommended that the patient be supported on a "tripod" consisting of a chest block and two lateral supports for the anterior superior iliac spines leaving the abdomen pendulous and free from extemal pressure. The moderate extension of the lumbar vertebral column resulting from this method of support was not considered a disadvantage during laminectomy.

2. The effect of I.P.P.R. The relationship between venous pressure and intrathoracic pressure was recognized by Valsalva. ${ }^{27}$ Any harmful effects of controlled ventilation are the result of the elimination of the normal negative intrathoracic pressure. Nagore ${ }^{23}$ demonstrated that any hindrance to venous return by a rise in intrathoracic pressure (e.g., by coughing, straining, or I.P.P.R.) can divert blood into the vertebral venous plexus. Venous return to the right heart is impeded as intrathoracic pressure rises. As a result, a rise in peripheral venous pressure compensates for the reduced venous return and resultant blood pressure fall, and it is dependent on normal vasomotor mechanisms and normal circulating blood volume. If severe blood loss occurs combined with a high mean intrathoracic pressure, further compensation becomes impossible and the result may be disastrous. ${ }^{2 \mathrm{~s}}$ 


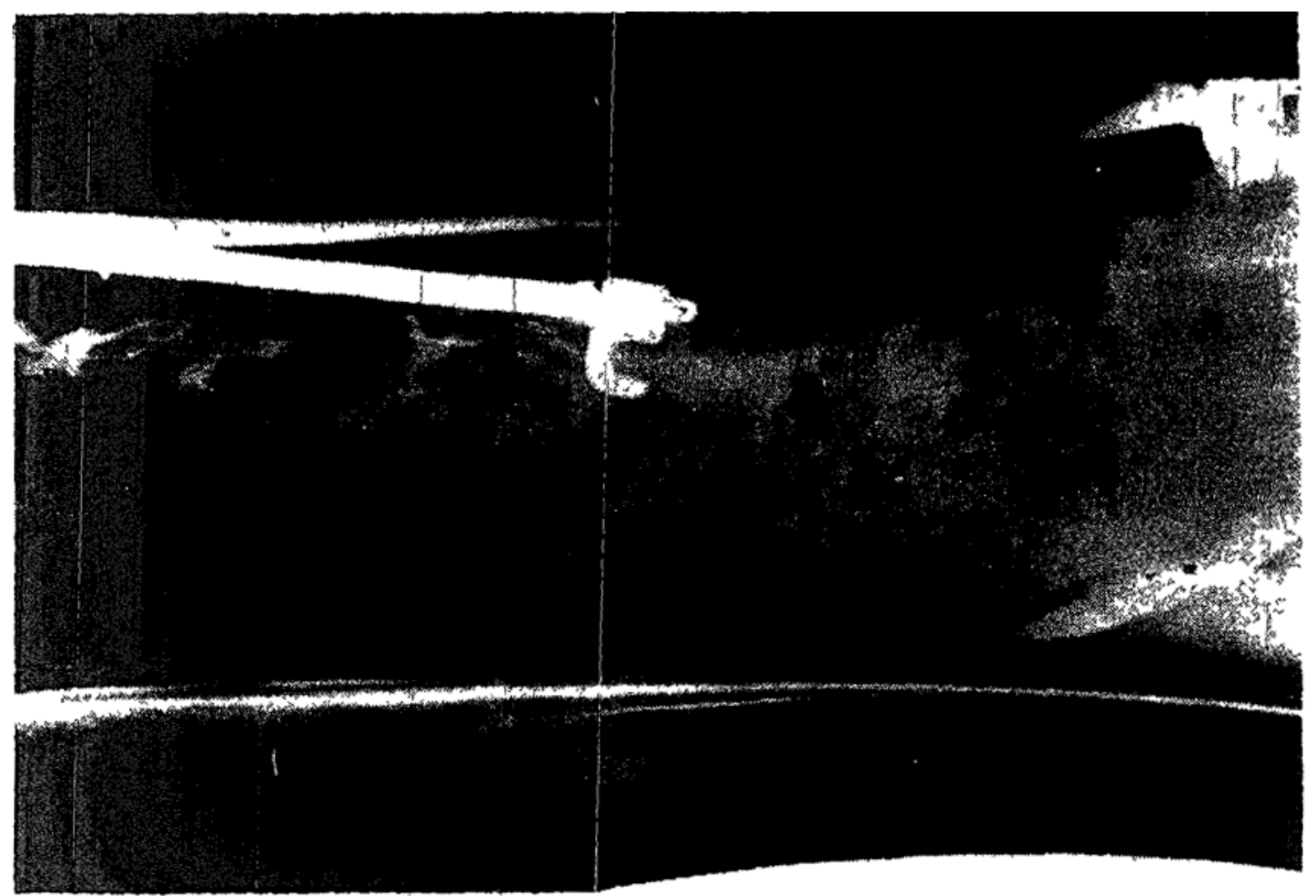

Fucure 5 Flow of contrast medium from the lower limb impeded by pressure on the anterior abdommal wall causing I.V.C. obstruction. Patient in prone position supported by the MacKay frame.

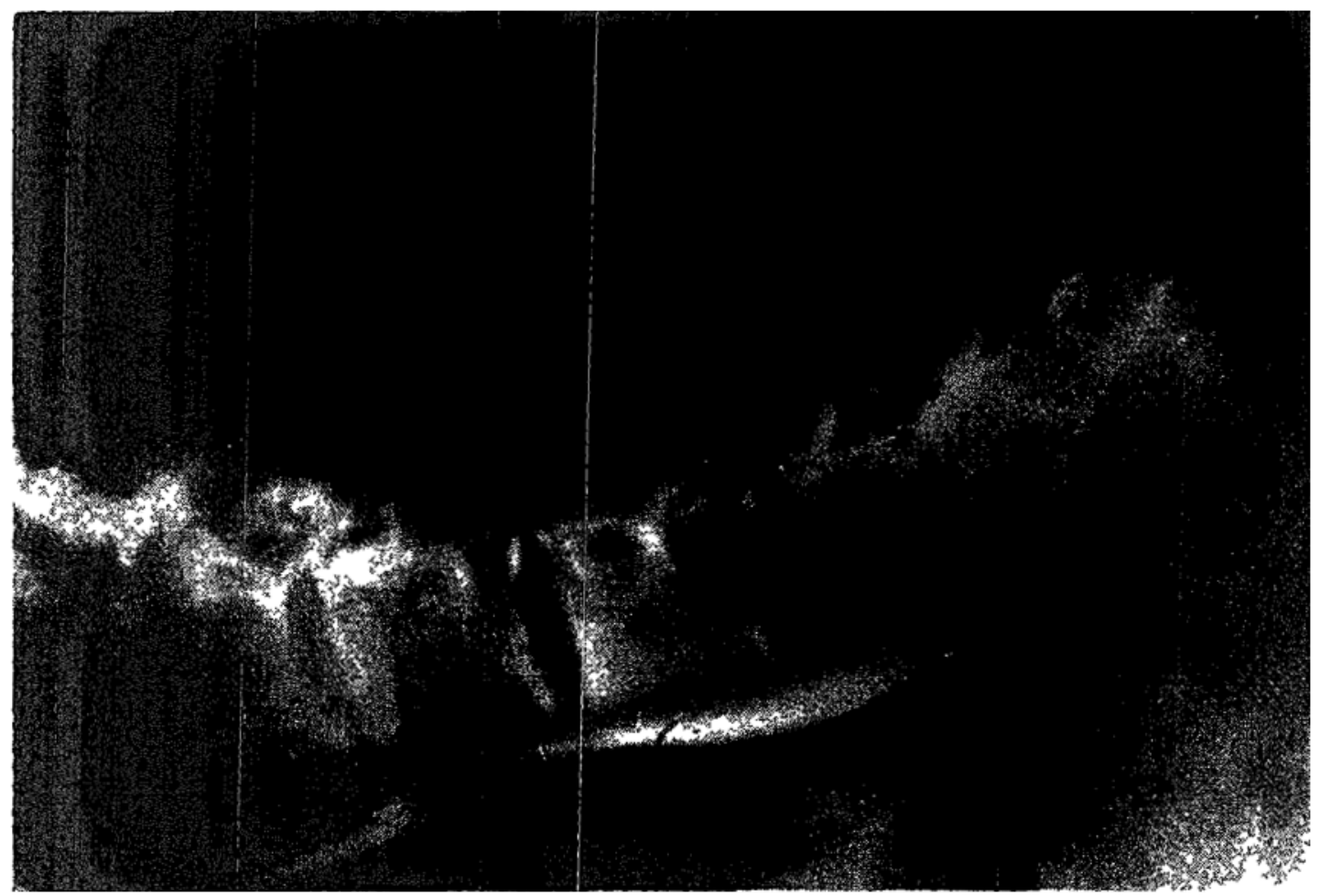

Frgune 6. Flow of contrast medium along I.V.C. Patient in prone position supported by the "tripod method." 


\section{Methods to Reduce Bloon Loss}

Blood loss during surgery may be reduced either by vasoconstriction which prevents the vessels from bleeding or by vasodilatation combined with pooling of blood in the dependent parts. Thus, various methods have been suggested to reduce haemorrhage in operations on the vertebral column.

Regional analgesia. Both spinal ${ }^{14}$ and epidural ${ }^{29,30}$ have been recommended. These techniques are considered unsuitable for use in children with severe scoliosis because: $(a)$ there is technical difficulty in the accurate placement of the analgesic drug; $(b)$ it would be necessary to extend the block into the cervical region with consequent undesirable complications; $(c)$ the possible association of the anaesthetic method with surgical neurological complications.

Induced hypotension by ganglion blocking agents. ${ }^{31}$ Hypotension is produced by increasing the capacity of the vascular bed in relation to the circulating blood volume. Vasodilatation produces pooling of the blood in the dependent parts with consequent diminished venous return and a fall in blood pressure. Posture is , utilized to facilitate venous drainage from the operative site but extreme positions may be necessary to obtain a satisfactory "bloodless" field. Children and adolescents are resistant to the effects of the ganglion blocking agents ${ }^{32}$ and tachyphylaxis frequently occurs especially with the methonium group pof drugs. It is considered that the prone posture and method of patient support necessary for extensive spinal fusion contraindicates a technique involving deliberate hypotension. Pressure on the anterior abdominal wall which compresses the I.V.C. against the vertebral bodies can reduce venous return to the point of acute circulatory failure. (A comparable situation has been described when the operating table bridge is elevated during hypotensive or even normotensive anaesthesia.. ${ }^{25,33}$ ) In addition, an increase rather than a diminution of bleeding may result because of the diversion of blood from the I.V.C. into the vertebral veins which take part in the generalized vasodilatation. ${ }^{25}$ This situation is particularly undesirable in a patient whose compensatory reflexes are depressed.

Local infiltration of a vasoconstrictor. ${ }^{19,16}{ }^{34}$ The $^{2}$ operative site is infiltrated from the skin to the transverse processes with a solution of adrenaline $(1: 250,000)$. A total dose of not more than $0.5 \mathrm{ml}$. of 1:1,000 adrenaline is given. The method has been effective in-reducing bleeding from the skin and superficial tissues but has little effect on the thin-walled deeper vessels or on oozing from the bony surfaces.

Posture. Use of the lateral posture diminishes bleeding during spinal operations but is unsuitable for this procedure. In this series only the prone position has been used in combination with one of the three methods of patient support previously described. Angiograms performed with the patient positioned on the MacKay frame have demonstrated I.V.C. obstruction (Fig. 5). The "tripod" method of chest block and lateral supports for the anterior" superior iliac spines seems preferable (Fig. 6). When this method is combined with muscle relaxation and the maintenance of a low mean intrathoracic pressure, blood loss is reduced. In many cases with gross deformity, however, the method provides inadequate support, producing hyperextension of the vertebral column and increasing the operative difficulties. 
Maintenance of a low mean intrathoracic pressure. During I.P.P.R., the inean intrathoracic pressure is elevated, impeding venous return to the right heart and causing a rise in peripheral venous pressure. These effects are minimized by maintaining a low mean intrathoracic presssure during the respiratory cycle. It may be accomplished as follows: ( $a$ ) the inspiratory phase should be as short as possible consistent with adequate gas exchange; $(b)$ there sheuld be minimal expiratory resistance; $(c)$ a negative pressure should be applied in the expiratory phase. ${ }^{28}$ Negative pressure during the expiratory phase is transmitted to the intrathoracic structures including the great veins and so aids venous return. A respiratory cycle consisting of positive, atmospheric and negative phases in the ratio of 1:1:1 has been recommended ${ }^{35}$ The benefits of a negative pressure in the expiratory phase can be combined with the advantages of hyperventilation. Maloney et al. ${ }^{36}$ found that hyperventilation in patients with circulatory disturbance was followed by a severe fall in blood pressure and cardiac output. These effects were minimal if a negative pressure was applied during the expiratory phase.

\section{SUMMARY}

In cases of severe scoliosis, some degree of respiratory disability may be present. If operative correction of the deformity is proposed, accurate assessment is required preoperatively and careful attention should be given to ventilation during anaesthesia and in the postoperative period. Measurements of ventilation have been taken pre- and post-operatively and an analysis of the results will be the subject of a future publication.

Blood loss may be severe during the operation of spinal fusion combined with Harrington rod instrumentation and adequate blood transfusion is essential. Methods to reduce blood loss are discussed.

An anaesthetic method is suggested which includes moderate hyperventilation combined with a negative phase in expiration. Local infiltration of the operative site with a vasoconstrictor is recommer ded. Meticulous attention should be given to the positioning of the patient and undue pressure on the anterior abdominal wall avoided.

\section{RÉSUMÉ}

Chez les porteurs de scoliose marquée, on observe un certain degré d'insuffsance respiratoire. Si l'on songe à corriger ce défaut par de la chirurgie, il s'impose de faire une évaluation exacte de la fonction respiratoire du malade avant l'opération; et au cours de l'anesthésie et des suites opératoires, il faut prêter une attention spéciale à la ventilation. Nous avons fait des mésures de la ventilation avant et après l'opération et une analyse des résultats fera l'objet d'un article à suivre.

Les pertes sanguines peuvent être considérables au cours d'une opérątion pour greffe vertébrale si l'on emploi le cerceau de Harrington et il s'impose que le remplacement du șang soit adéquat. Parmi les méthodes suggérées en temps ordinaire pour diminuer les pertes sanguines, la rachianesthésie ou l'épidurale. sont déconseillées chez les enfants porteurs de scoliose marquée. Nous sommes 
d'opinion que la position ventrale et la façon de placer le malade pour faire une longue greffe contrindiquent l'hypotension contrôlée. A part cela, il peut résulter une augmentation plutôt qu'une diminutión de l'hémorragie à cause de la déviation du sang de la veine cave inférieure vers les veines vertébrales qui subissent la vasodilatation généralisée. ${ }^{25}$ Une infiltration locale de la peau aux apophyses transverses avec une solution d'adrénaline 1:250,000 peut réussir à diminuer le suintement sanguin de la peau et des tissus superficiels mais cela n'a que très peu d'effet sur les vaisseaux plus profonds à paroi mince ou sur le suintement des surfaces osseuses. L'usage de la position latérale diminue les pertes de sang au cours de la greffe vertébrale mais cette position est peu pratique pour ce genre de travail.

On peut diminuer les pertes sanguines en maintenant une pression moyenne intrathoracique basse. On arrive à ce but en créant une phase négative à l'expiration. Nous conseillons un cycle respiratoire consistant en une pression positive égale à la pression atmosphérique et des phases négatives dans la proportion dé 1:1:1. La technique d'anesthésie conseillée comprend une hyperventilation légère associée à une phase négative à l'expiration. Nous conseillons également une infiltration du site opératoire avec une solution v'dsoconstrictrice. Il faut faire grande attention pour placer le malade et éviter toute pression sur la paroi abdominale antérieure.

\section{ACKNOWLEDGMENT}

The authors would like to thank Dr. John Hall of the Hospital for Sick Children, Toronto, for permission to report these cases, and the following Residents for their assistance: Dr. E. Oliver, Dr. S. Nabeta, Dr. B. Wilson, Dr. W. M. Brummitt, Dr. S. Sims.

\section{REFERENCES}

1. U.S. Selective Service System, Medical Statistics Bulletin No. 2. Causes of Rejection and Incidence of Defects. Washington, D.C. (1943). Quoted by E. H. BergofsKY et al., Ref. 5.

2. Risser, J. C. \& Ferguson, A. B. Scoliosis: Its Prognosis. J. Bone \& Joint Surg. 18: 667 (1936).

3. Harrington, P. R. Treatment of Scoliosis. Correction and Internal Fination by Spine Instrumentation. J. Bone \& Joint Surg. 44A: 591 ( 1962).

4. Ferguson, A. B. Orthopaedic Surgery in Infancy and Childhood. Ist ed. Baltimore. The Williams and Wilkins Co. (1957).

J. Bergofskx, E. H.; Turino, G. M.; \& Fisharan, A. P. Cardiorespiratory Failure in Kyphoscoliosis. Medicine 38: 263 (1959).

6. Caro, C. G. \& Dubors, A. B. Pulmonary Function in Kyphoscoliosis. Thoras 16: 282 (1961).

7. Zorab, P. A. The Lungs in Kyphoscoliosis. Developmental Med. \& Chitd Neurol. 4: 339 (1962).

8. Abramamson, M. L. Pulmocardiac Failure Associated with Deformity of the Chest. Lancet i: 205 (1959).

9. Prime, F. J. Symposium on the Lungs in Chest Deformity. Thorax 17: 287 (1962).

10. Editorial. Lancet i: 205 (1963).

11. Hall, J. Personal communication (1963):

12. Robinson, J. S. Modern Trends in Anaesthesia, vol. 2, edited by F. T. Evins and T. C. Gray. 1st ed. London: Butterworths (1962). 
13. Riming, J. E. \& Robinson, J. S. The Safety of Neostigmine. Anaesthesia 16: 346 (-1961).

14. Hunter, A. R. Anaesthesia for Operations on the Vertebral Canal. Anesthesiology 11: 367 (1950).

15. MacKay, I. M. A New Frame for the Positioning of Patients for Surgery of the Back. Canad. Anaesth. Soc. I. 3: 279 (1956).

16. Pearce, D. J. The Role of Posture in Laminectomy. Proc. Roy. Soc. Med. 50: 109 (1957).

17. Smirh, C. H. Blood Diseases of Infancy and Childhood. 1st ed. St. Lous: C. V. Mosby Co $(1960)$.

18. BonICA, J. J. \& LYTER, C. S. Blood Loss during Surgical Operations. Anesthesiology 12 : 90 (195i).

19. Goldstenn, L. A. The Surgital Treatment of Scolosis. 1st ed. Springfield, Ill.: Charles C. Thomas (1959).

20. Molisson, P. L. Blood Transfusion in Clinical Medicine. 3rd ed. Springfield, Illinois, Charles C. Thomas, 1961.

21. Cruveilmier. Anatomie Descriptive. Vol. 3, p. 328. Paris (1834). Quoted by M. Nagore, Ref. 23.

22. McGregor, A. LEe. A Synopsis of Surgical Anatomy. 7th ed. Bristol: John Wright and Sons (1950).

23. Nagone, M. Clinical Anatomy of the Vertebral Veins. Surgery 17: 606 (1945).

24. Batson, $O$. V. The Function of the Vertebral Veins and Their Role in the Spread of Metastasis. Ann. Surg. 112: 138 (1940).

25. Scotr, D. B. Inferior Vena Caval Pressure. Changes Occurring during Anaesthesia. Anaesthesia 18: 135 (1963).

26. Rolrason, W. N. Anaesthesia and the "Bloodless" Field. Curr. Res. Anaesth. 32: 289 (1953).

27. Valsalva. Cited by K. J. Frankin. A Monograph on Veins. Springfield, Ill.: Charles C. Thomas (1937).

28. Mushin, W. W.; Rendell, Baker L.; \& Thompson, P. W. Automatic Ventilation of the Lungs. 1st ed. Oxford: Blackwells (1959).

29. Bhomage, P. R. Vascular Hypotension in 107 Cases of Epidural Analgesia. Anaesthesia 6: 26 (1951).

30. Bromage, P. R. Lumbar Fpidural Analgesia for Major Surgery below the Diaphragm. Anaesthesia 7: 171 (1952).

31. Enderay, G. E. H. Discussion on the Use of Hypotensive Drugs in Surgery. Proc. Roy. Soc. Med. 44: 829 (1951).

32. Anderson, S. M. Controlled Hypotension with Arfonad in Paediatric Surgery. Brit. Med. J. ii: 103 (1955).

33. Soper, R. L. Personal Communication (1959).

34. Fretberg, J. A. \& Perlman, R. Local Infiltration Anaesthesia in Spine Surgery. J. Bone \& Joint Surg. 25: 145 (1943).

35 Dobkrn, A. B. \& Wrant, G. M. Anaesthesia with Controlled Positive and Negative Pressure Respiration. Review of Cardiorespiratory Function and Acid-Băse Homeostasis. Brit. J. Anaesth. 28: 353 (1956).

36. Maloney, J. V; Elam, J. O.; Handford, S. W.; Balla, G. A.; Eastwood, D. W.; Brown, E. St, \& TenPAs, R. H. The Importance of Negative Pressure Phase in Mechanical Respirators. J.A.M.A. 152: 212 (1953). 